\title{
Anatomical Basis of Pronator Teres for Electromyography Needle Placement Using Ultrasonography
}

\author{
Myung Kyu Park, MD, In Yae Cheong, MD, Ki Hoon Kim, MD, PhD, \\ Byung Kyu Park, MD, PhD, Dong Hwee Kim, MD, PhD
}

Department of Physical Medicine and Rehabilitation, Korea University College of Medicine, Seoul, Korea

\begin{abstract}
Objective To find the optimal needle insertion site for needle electromyography of the pronator teres (PT) muscle among commonly used sites.

Methods Fifty forearms of 25 healthy subjects were evaluated. Four expected needle insertion points were designated as follows. Point 0 was positioned at the midpoint between the medial epicondyle and medial border of biceps tendon in the elbow crease. Points 1, 2, and 3 were located $2 \mathrm{~cm}, 3.5 \mathrm{~cm}$ and $5 \mathrm{~cm}$ distal to point 0 , respectively. We assumed that the thickness of PT and the distances between a vertical line from each point to the medial margin of the PT were significant parameters for finding the optimal site. Thus, we measured these parameters through ultrasonographic examination.

Results In men, the PT was thickest at point 2, and in women, at point 1 . The distance between the expected needle insertion line and medial margin of PT was longest at point 1 in both men and women, and was statistically significant compared to points 2 and 3. Both men and women had neurovascular bundles located lateral to the expected needle insertion line.

Conclusion The most appropriate and safe needle electromyographic insertional site for the PT is 2-3.5 cm distal to the mid-point between the biceps tendon and medial epicondyle in the elbow crease and the needle should be inserted upward and medial.
\end{abstract}

Keywords Forearm, Electromyography, Ultrasonography

Received June 30, 2014; Accepted September 1, 2014

Corresponding author: Dong Hwee Kim

Department of Physical Medicine and Rehabilitation, Korea University Ansan Hospital, 123 Jeokgeum-ro, Danwon-gu, Ansan 425-707, Korea Tel: +82-31-412-5330, Fax: +82-31-412-5344, E-mail: rmkdh@korea.ac.kr

(c) This is an open-access article distributed under the terms of the Creative Commons Attribution Non-Commercial License (http://creativecommons. org/licenses/by-nc/3.0) which permits unrestricted noncommercial use, distribution, and reproduction in any medium, provided the original work is properly cited.

Copyright $\odot 2015$ by Korean Academy of Rehabilitation Medicine

\section{INTRODUCTION}

Since the pronator teres (PT) muscle is innervated by the median nerve from the lateral cords of the brachial plexus, originating from the ventral roots of $\mathrm{C} 6$ and $\mathrm{C} 7$, needle electromyography of this muscle is useful for evaluating brachial plexopathy, cervical radiculopathy, median neuropathy, or anterior interosseous nerve syndrome.

The identification of an optimal needle electrode inser- 
tion point is important for obtaining optimal motor unit action potentials and minimizing patient discomfort and complications. The commonly used method of needle electrode insertion is inserting the needle two fingerbreadths distal to the mid-point between the biceps tendon and medial epicondyle with the forearm supinated $[1,2]$.

Electrodiagnostic procedures are generally well tolerated and rarely thought to be associated with any significant complications. However, there can be iatrogenic complications, including bleeding, infection, and nerve damage from the procedure [3]. Needle insertion for needle electromyography of the PT muscle requires more caution because the median nerve and brachial or ulnar artery are close to the PT muscle. In addition, if the needle is inserted too medially, it may reach other muscles such as the flexor carpi radialis [4]. Thus, a reliable and safe technique for inserting a needle electrode into the PT muscle has to be explored in order to prevent serious neurovascular complications. The aim of this study is to provide an accurate and safe approach to needle insertion through identifying the anatomical relationship between the common needle electrode insertion site of the PT muscle and the neurovascular bundle using ultrasonography, and to suggest an optimal needle insertion location.

\section{MATERIALS AND METHODS}

The study group was composed of 13 men and 12 women, with a mean ( \pm standard deviation) age of $31.7( \pm 10.0)$ years. The 25 volunteers had no history of neuromuscular disease, exhibited normative findings in a neurologic examination, and were currently not taking any medication. Assessments were taken on both forearms for all subjects, thus, there were 50 forearms were measured in total. This study protocol was approved by the Institutional Review Board. All subject participated voluntarily in this study and consent forms were signed by each of them.

Height, weight, and circumference and length of both forearms were measured. The forearm circumference was measured at $3.5 \mathrm{~cm}$ distal to the elbow crease. The length of the forearm was defined as the distance from the ulnar styloid process to the olecranon with the forearm supinated and the elbow at $90^{\circ}$ in a supine position.
The mid-point between the biceps tendon and medial epicondyle at the elbow crease was marked with a pen. For the landmark of ultrasonographic evaluation, an epidural needle (22-guage, $80 \mathrm{~mm}$ long) with the needle-tip broken off was placed to the marked point parallel to the medial side of forearm (Fig. 1).

Ultrasonographic scanning was done at four pointsthe marked point in the elbow crease (point 0 ), $2 \mathrm{~cm}$ distal to point 0 (point 1 ), $3.5 \mathrm{~cm}$ distal to point 0 (point 2), and $5 \mathrm{~cm}$ distal to point 0 (point 3). Although one finger breadth is defined as $3 / 4$ inch, which is about $1.9 \mathrm{~cm}$ [5], we assumed two fingerbreadths to be $3.5 \mathrm{~cm}$. A high-resolution, real-time ultrasonography was performed by an expert physiatrist using the Accuvix V20 system (Samsung Medison, Seoul, Korea) interfaced with a 5-13 MHz linear array transducer. Ultrasonographic examinations of the PT muscle were performed in a transverse view with subjects in a supine position with their elbows fully extended and forearms supinated.

At each point of scanning, the distance between each point and upper margin of PT (S_PT1), the distance between each point and lower margin of PT (S_PT2), the distance between vertical line of each point and medial margin of PT and lateral margin of PT (P_PT1 and P_PT2,

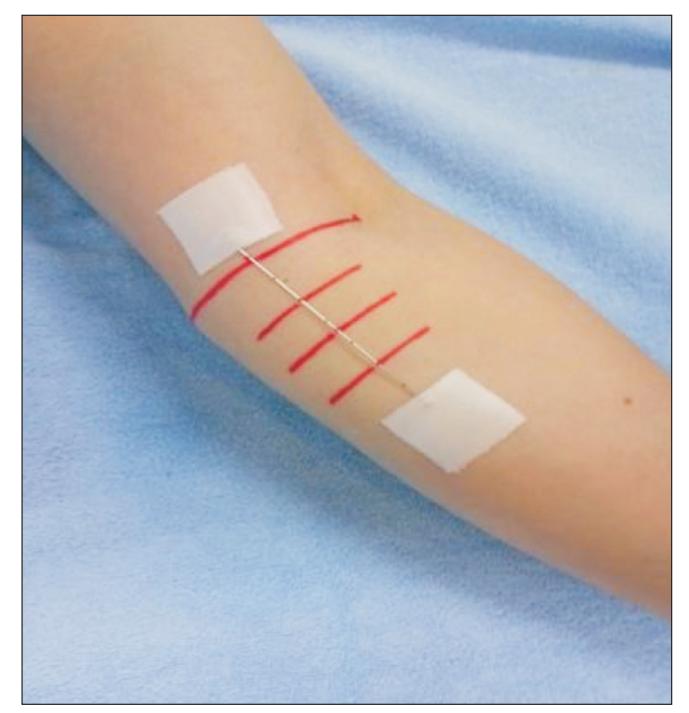

Fig. 1. Ultrasonography of the forearm with the transducer located at the four sites of the forearm in transverse plane. Point 0 , the mid-point between the biceps tendon and medial epicondyle in the elbow crease; point $1,2 \mathrm{~cm}$ distal to point 0 ; point $2,3.5 \mathrm{~cm}$ distal to point 0 ; point 3 , $5 \mathrm{~cm}$ distal to point 0 . 
respectively), the distance between vertical line of each point and medial margin of brachial or ulnar artery and median nerve (P_A and P_MN, respectively), and the angle between the vertical line of the each point and medial border of ulnar or brachial artery and median nerve ( $\mathrm{A}_{-}$ A and A_MN) were measured. If the medial end of the PT was located lateral to the vertical line of each point, the P_PT1 was recorded as a negative value (-) (Fig. 2). We as- sumed that the thickness of the PT at each point and the horizontal distances from the vertical line of each point to the medial margin of PT were significant parameters for deciding the ideal needle insertion point by ultrasonography.

All statistical analyses were performed with the SPSS ver. 20.0 (IBM SPSS Inc., Armonk, NY, USA). The independent t-test was performed to compare the height,
(A)

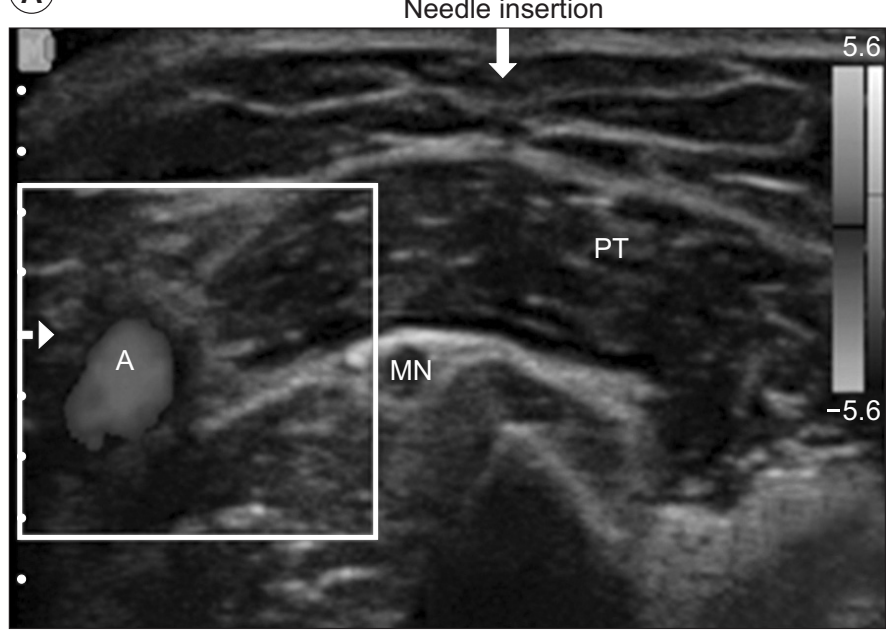

Needle insertion

(B)

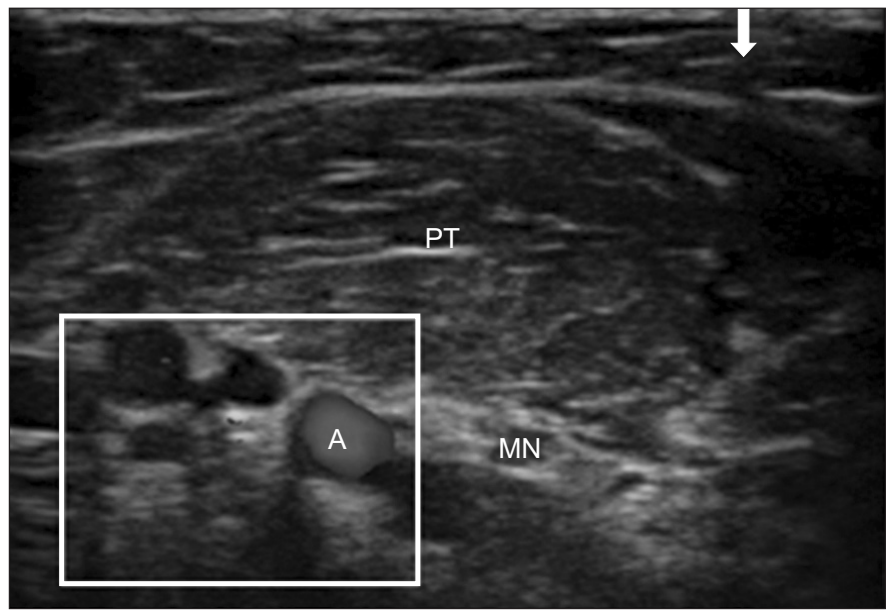

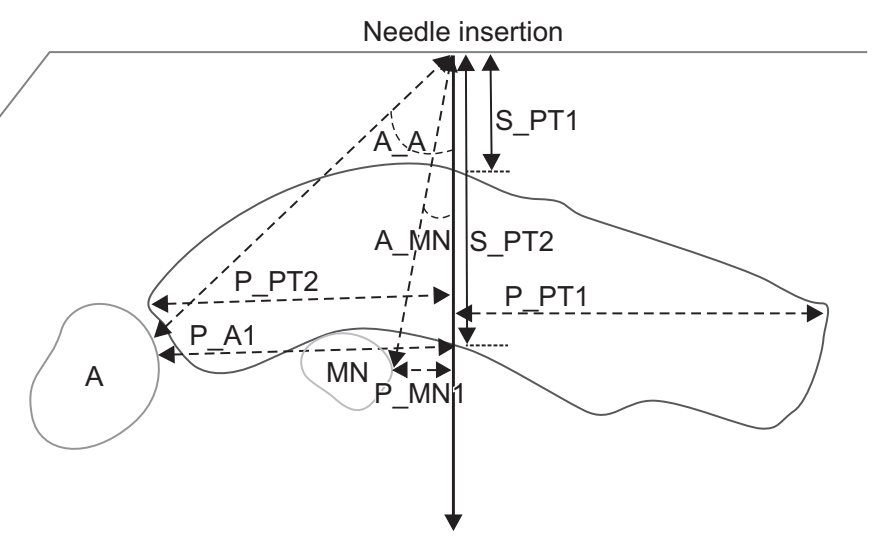

Needle insertion

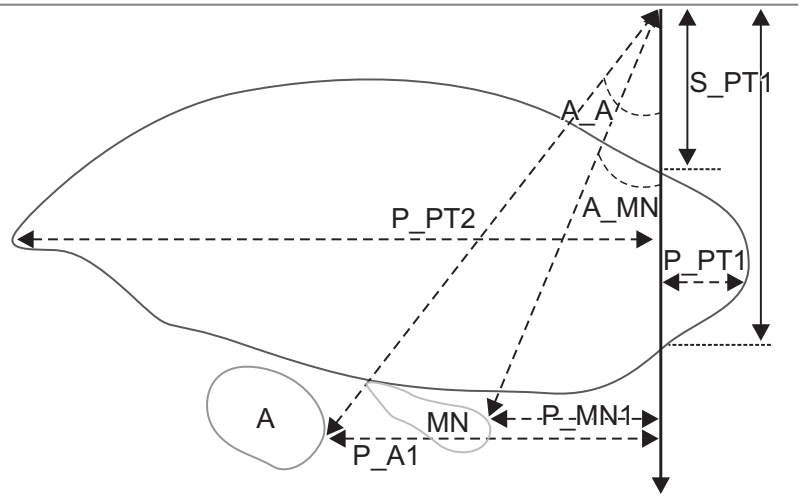

Fig. 2. Transverse view of ultrasonographic images with schematic drawing obtained at the forearm of a female at $2 \mathrm{~cm}$ distal to the elbow crease (point $1 ; \mathrm{A}$ ) and at $3.5 \mathrm{~cm}$ distal to the elbow crease (point 2; B). Needle insertion site presents as a hypoechoic focus with well-defined posterior acoustic shadowing (arrow). PT, pronator teres muscle; A, ulnar artery; MN, median nerve; S_PT1, the distance between each point and the upper margin of the pronator teres; S_PT2, the distance between each point and the lower margin of the pronator teres; P_PT1, the distance between the vertical line of each point and the medial margin of the pronator teres; P_PT2, the distance between the vertical line of each point and the lateral margin of the pronator teres; P_MN, the distance between the vertical line of each point and the medial margin median nerve; $P_{-} A$, the distance between the vertical line of each point and the medial margin of brachial or ulnar artery; A_MN, the angle between the vertical line of the each point and the medial border of the median nerve; A_A, the angle between the vertical line of the each point and the medial border of the brachial or ulnar artery. 
Table 1. Comparison of weight, height, circumference and length of forearm, and thickness and width of pronator teres (PT) muscle between men and women

\begin{tabular}{lrr}
\hline \multicolumn{1}{c}{ Parameter } & \multicolumn{1}{c}{ Men } & \multicolumn{1}{c}{ Women } \\
\hline Weight $(\mathrm{kg})$ & $72.77 \pm 6.29$ & $53.00 \pm 9.43^{*}$ \\
Height $(\mathrm{cm})$ & $176.46 \pm 5.41$ & $159.33 \pm 6.85^{*}$ \\
Forearm circumference $(\mathrm{cm})$ & $26.48 \pm 0.88$ & $22.33 \pm 1.73^{*}$ \\
Forearm length $(\mathrm{cm})$ & $27.05 \pm 1.14$ & $23.18 \pm 1.87^{*}$ \\
Level 0 & & \\
PT thickness (cm) & $0.72 \pm 0.27$ & $0.50 \pm 0.25^{*}$ \\
PT width (cm) & $3.13 \pm 0.57$ & $2.30 \pm 0.46^{*}$ \\
Level 1 & & \\
PT thickness (cm) & $1.11 \pm 0.26$ & $0.81 \pm 0.22^{*}$ \\
PT width (cm) & $3.45 \pm 0.54$ & $2.62 \pm 0.26^{*}$ \\
Level 2 & & \\
PT thickness (cm) & $1.26 \pm 0.34$ & $0.80 \pm 0.30^{*}$ \\
PT width (cm) & $3.34 \pm 0.65$ & $2.42 \pm 0.30^{*}$ \\
Level 3 & & \\
PT thickness (cm) & $0.63 \pm 0.53$ & $0.05 \pm 0.14^{*}$ \\
PT width (cm) & $2.56 \pm 0.72$ & $1.95 \pm 0.36^{*}$ \\
\hline
\end{tabular}

Values are presented as mean \pm standard deviation. ${ }^{*} \mathrm{p}<0.05$. weight, circumference and length of forearms between men and women. The measured distance and angle of artery and nerve at points $0,1,2$, and 3 were compared using an analysis of variance for repeated measurements and Bonferroni adjustment. In order to test whether the sphericity assumption was accurate, we also ran a Mauchly sphericity test. If the sphericity assumption was violated $(p<0.05)$, the Greenhouse-Geisser correction was performed to estimate the $\mathrm{p}$-value. Also, if it was not violated, we used the exact $\mathrm{p}$-values. The $\mathrm{p}$-values under 0.05 were considered as statistically significant.

\section{RESULTS}

The mean \pm standard deviation of weight, height, and circumference and length of the forearm were $63.28 \pm$ $12.78 \mathrm{~kg}, 168.24 \pm 10.61 \mathrm{~cm}, 24.53 \pm 2.49 \mathrm{~cm}$, and $25.19 \pm 2.49$ $\mathrm{cm}$, respectively. There was a significant difference between the results obtained from men and women (Table 1).

In men, the muscle was thickest at point 2 and showed a statistically significant difference with points 0 and 3

Table 2. Ultrasonographic parameters of pronator teres muscle in men $(\mathrm{n}=26)$

\begin{tabular}{lccccc}
\hline & Level 0 & Level 1 & Level 2 & Level 3 & p-value \\
\hline S_PT1 $(\mathrm{cm})$ & $0.45 \pm 0.20^{\mathrm{a})}$ & $0.38 \pm 0.17^{\mathrm{b})}$ & $0.67 \pm 0.26^{\mathrm{c})}$ & $0.52 \pm 0.48$ & 0.000 \\
\hline S_PT2 $(\mathrm{cm})$ & $1.29 \pm 0.54^{\mathrm{d})}$ & $1.79 \pm 1.16^{\mathrm{e})}$ & $1.95 \pm 0.41^{\mathrm{f})}$ & $1.24 \pm 0.91^{\mathrm{g})}$ & 0.000 \\
\hline P_PT1 $(\mathrm{cm})$ & $1.72 \pm 0.51^{\mathrm{h})}$ & $1.47 \pm 0.51^{\mathrm{i})}$ & $0.94 \pm 0.58^{\mathrm{j})}$ & $0.05 \pm 0.30^{\mathrm{j})}$ & 0.000 \\
\hline P_PT2 $(\mathrm{cm})$ & $1.41 \pm 0.51^{\mathrm{j})}$ & $2.00 \pm 0.52^{\mathrm{j})}$ & $2.40 \pm 0.49^{\mathrm{j})}$ & $2.51 \pm 0.75^{\mathrm{j})}$ & 0.000 \\
\hline P_MN $(\mathrm{cm})$ & $1.27 \pm 0.41^{\mathrm{h})}$ & $1.49 \pm 0.50$ & $1.58 \pm 0.55^{\mathrm{a})}$ & $1.71 \pm 0.44^{\mathrm{k})}$ & 0.002 \\
\hline P_A $(\mathrm{cm})$ & $1.77 \pm 0.42$ & $1.94 \pm 0.41$ & $1.88 \pm 0.44$ & $1.88 \pm 0.52$ & 0.152 \\
\hline A_MN $\left({ }^{\circ}\right)$ & $59.14 \pm 10.47^{\mathrm{h})}$ & $53.40 \pm 10.75^{\mathrm{j})}$ & $44.23 \pm 13.30^{\mathrm{c})}$ & $41.26 \pm 9.02^{\mathrm{l})}$ & 0.000 \\
\hline A_A $\left({ }^{\circ}\right)$ & $62.91 \pm 6.72^{\mathrm{h})}$ & $59.56 \pm 7.57^{\mathrm{i})}$ & $47.56 \pm 9.31^{\mathrm{c}}$ & $43.08 \pm 8.39^{\mathrm{l})}$ & 0.000 \\
\hline Thickness $(\mathrm{cm})$ & $0.72 \pm 0.27^{\mathrm{m})}$ & $1.11 \pm 0.26^{\mathrm{n})}$ & $1.26 \pm 0.34^{\mathrm{f})}$ & $0.63 \pm 0.53^{\mathrm{o})}$ & 0.000 \\
\hline Width $(\mathrm{cm})$ & $3.13 \pm 0.57^{\mathrm{k})}$ & $3.45 \pm 0.54^{\mathrm{p})}$ & $3.34 \pm 0.65^{\mathrm{g})}$ & $2.56 \pm 0.72^{\mathrm{j})}$ & 0.000 \\
\hline
\end{tabular}

Values are presented as mean \pm standard deviation.

S_PT1, the distance between each point and the upper margin of the pronator teres; S_PT2, the distance between each point and the lower margin of pronator teres; P_PT1, the distance between the vertical line of each point and the medial margin of the pronator teres; P_PT2, the distance between the vertical line of each point and the lateral margin of the pronator teres; $P_{-}$MN, the distance between the vertical line of each point and the medial margin of the median nerve; $\mathrm{P} \_\mathrm{A}$, the distance between the vertical line of each point and medial margin of the brachial or ulnar artery; A_MN, the angle between the vertical line of each point and medial border of the median nerve; A_A, the angle between the vertical line of the each point and medial border of the brachial or ulnar artery.

${ }^{a)} p<0.05$, between level 0 and level 2; ${ }^{b} p<0.05$, between level 1 and level 2 ; ${ }^{c} p<0.05$, between level 2 and level 0,$1 ;{ }^{d)} p<0.05$, between level 0 and level 1,$2 ;{ }^{\mathrm{e}} \mathrm{p}<0.05$, between level 1 and level $0 ;{ }^{\mathrm{f})} \mathrm{p}<0.05$, between level 2 and level 0,$3 ;{ }^{\mathrm{g}} \mathrm{p}<0.05$, between level 3 and level $2 ;{ }^{\mathrm{h}} \mathrm{p}<0.05$, between level 0 and level 2,3 ; ${ }^{\mathrm{i}} \mathrm{p}<0.05$, between level 1 and level 2,$3 ;{ }^{\mathrm{j})} \mathrm{p}<0.05$, among four levels; ${ }^{\mathrm{k}}$ $\mathrm{p}<0.05$, between level 0 and level $3 ;{ }^{1)} \mathrm{p}<0.05$, between level 3 and level 0,$1 ;{ }^{\mathrm{m})} \mathrm{p}<0.05$, between level 0 and level 1,$2 ;{ }^{\mathrm{n}} \mathrm{p}<0.05$, between level 1 and level 0,$3 ;{ }^{\circ)} \mathrm{p}<0.05$, between level 3 and level 2,$3 ;{ }^{\mathrm{p})} \mathrm{p}<0.05$, between level 3 and level 1 . 
Level 0

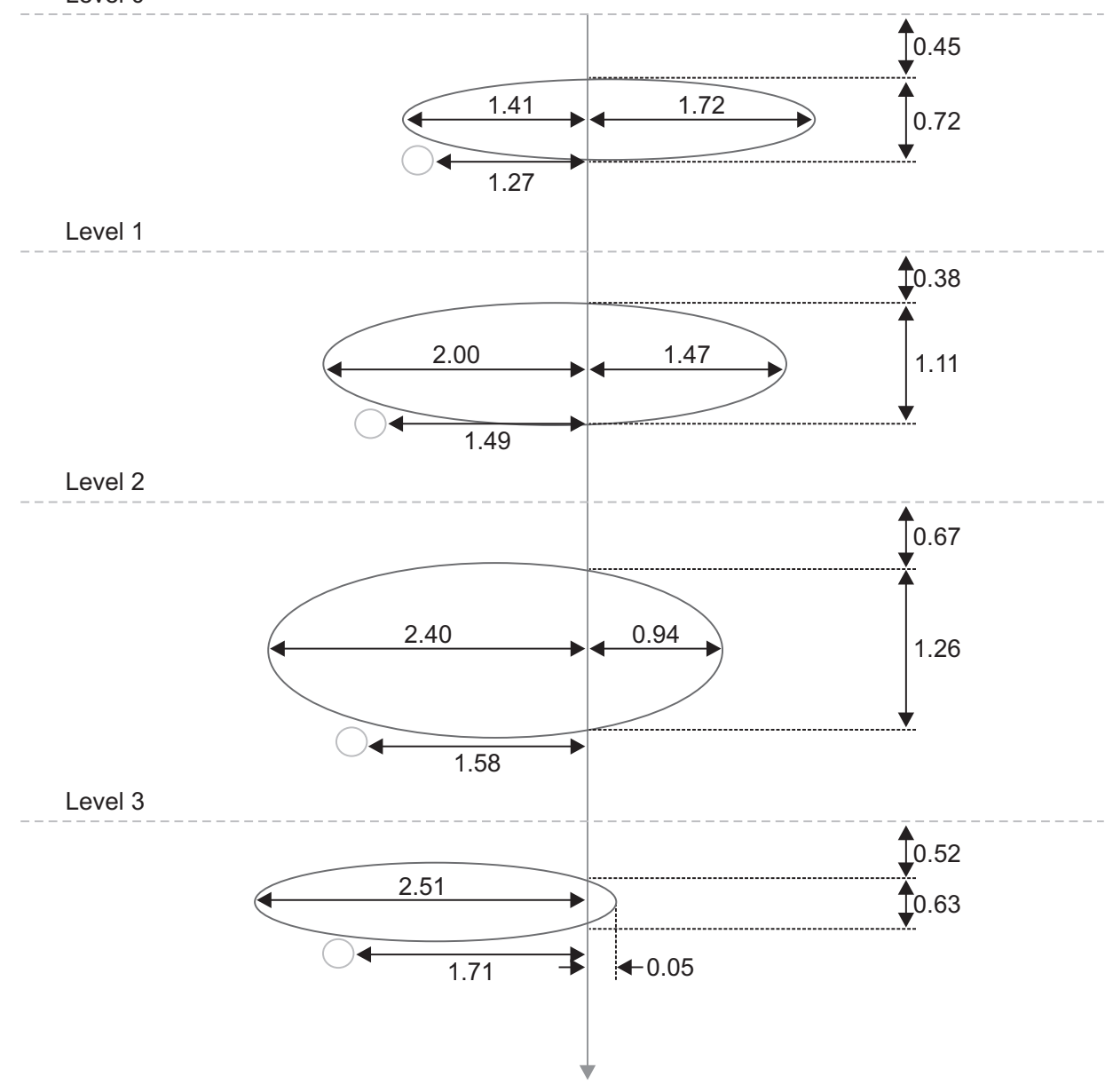

Fig. 3. In men, a schematic drawing of relationship of the distance between the vertical needle insertion line (red arrow) and the medial or lateral margin of the pronator teres (orange oval), the distance between the vertical needle insertion line and the medial margin of median nerve (yellow circle), and the distance between the skin (yellow dot line) and upper or lower margin of pronator teres. but not with point 1 . The distance between the vertical line from each point and medial margin of PT was longest at point 1 and showed a significant difference with points 2 and 3. The minimum value of P_PT1 was $0.96 \mathrm{~cm}$ at point 1 and $0.36 \mathrm{~cm}$ at point 2 (Table 2, Fig. 3). P_MN was longer at point 2 than at point 1 , and $\mathrm{P} \_\mathrm{A}$ was longer at point 1 than at point 2. However, P_MN and P_A at point 1 did not show any statistically significant difference with point 2. P_A was longer than P_MN at all points.

In women, the muscle was thickest at point 1 and showed a statistically significant difference with points 0 and 3 but not with point 2 . The distance between a vertical line from each point and the medial margin of the PT muscle was longest at point 1 , which was significantly different from points 2 and 3. The minimum value of P_PT1 was $0.53 \mathrm{~cm}$ at point 1 and $0.16 \mathrm{~cm}$ at point 2 . At point 3 , the P_PT1 was measured to be a negative value since the vertical line and the PT muscle did not overlap (Table 3, Fig. 4). $P \_M N$ and $P \_A$ at point 1 were longer than at point 2.
P_MN and P_A at point 1 did not have a statistically significant difference with point 2 . Also, as in men, the P_A was longer than $\mathrm{P} \_\mathrm{MN}$ at all points. Therefore, a vertical line was closer to the median nerve than the ulnar artery.

\section{DISCUSSION}

Despite variations in the muscular branches of the median nerve [6], the nerve usually arises from the cubital fossa and gives off a branch to PT muscle before entering between the two heads of the PT muscle. There are also variations in the course of the brachial or ulnar artery [7]. In general, the brachial artery divides into the radial and ulnar arteries proximal to the PT muscle, and ulnar artery passes obliquely downward, seated deeply, and covered by the PT [8].

Through the development of ultrasound resolution, the relative anatomical position of the neurovascular structures (the median nerve and brachial or ulnar arteries) to 
Table 3. Ultrasonographic parameters of pronator teres muscle in women $(n=24)$

\begin{tabular}{lccccc}
\hline & Level 0 & Level 1 & Level 2 & Level 3 & p-value \\
\hline S_PT1 $(\mathrm{cm})$ & $0.54 \pm 0.20^{\mathrm{a})}$ & $0.52 \pm 0.27^{\mathrm{b})}$ & $0.72 \pm 0.34^{\mathrm{c})}$ & $1.11 \pm 0.31^{\mathrm{d})}$ & 0.000 \\
\hline S_PT2 $(\mathrm{cm})$ & $1.11 \pm 0.46^{\mathrm{a})}$ & $1.26 \pm 0.49^{\mathrm{e})}$ & $1.37 \pm 0.86^{\mathrm{f})}$ & $0.16 \pm 0.49^{\mathrm{d})}$ & 0.000 \\
\hline P_PT1 $(\mathrm{cm})$ & $0.94 \pm 0.41^{\mathrm{g})}$ & $0.92 \pm 0.39^{\mathrm{b})}$ & $0.52 \pm 0.36^{\mathrm{d})}$ & $-0.26 \pm 0.22^{\mathrm{d})}$ & 0.000 \\
\hline P_PT2 $(\mathrm{cm})$ & $1.36 \pm 0.49^{\mathrm{d})}$ & $1.70 \pm 0.49^{\mathrm{d})}$ & $1.90 \pm 0.37^{\mathrm{d})}$ & $2.20 \pm 0.43^{\mathrm{d})}$ & 0.000 \\
\hline P_MN $(\mathrm{cm})$ & $1.27 \pm 0.48$ & $1.15 \pm 0.43$ & $1.02 \pm 0.30$ & $1.20 \pm 0.42$ & 0.018 \\
\hline P_A (cm) & $1.77 \pm 0.41$ & $1.68 \pm 0.40$ & $1.46 \pm 0.46$ & $1.48 \pm 0.55$ & 0.042 \\
\hline A_MN $\left({ }^{\circ}\right)$ & $58.51 \pm 11.39^{\mathrm{d})}$ & $47.13 \pm 12.53^{\mathrm{d})}$ & $39.10 \pm 11.23^{\mathrm{h})}$ & $35.98 \pm 11.70^{\mathrm{i})}$ & 0.000 \\
\hline A_A $\left(^{\circ}\right)$ & $63.53 \pm 4.64^{\mathrm{d})}$ & $56.00 \pm 7.50^{\mathrm{d})}$ & $39.10 \pm 11.23^{\mathrm{h})}$ & $35.98 \pm 11.70^{\mathrm{i})}$ & 0.000 \\
\hline Thickness $(\mathrm{cm})$ & $0.51 \pm 0.25^{\mathrm{d})}$ & $0.81 \pm 0.22^{\mathrm{j})}$ & $0.80 \pm 0.30^{\mathrm{k})}$ & $0.05 \pm 0.14^{\mathrm{d})}$ & 0.000 \\
\hline Width $(\mathrm{cm})$ & $2.30 \pm 0.46^{\mathrm{l})}$ & $2.62 \pm 0.23^{\mathrm{j})}$ & $2.41 \pm 0.30^{\mathrm{f})}$ & $1.95 \pm 0.36^{\mathrm{d})}$ & 0.000 \\
\hline
\end{tabular}

Values are presented as mean \pm standard deviation.

S_PT1, the distance between each point and the upper margin of pronator teres; S_PT2, the distance between each point and the lower margin of pronator teres; P_PT1, the distance between the vertical line of each point and the medial margin of the pronator teres; P_PT2, the distance between the vertical line of each point and the lateral margin of the pronator teres; P_MN, the distance between vertical line of each point and the medial margin median nerve; $P_{-} A$, the distance between the vertical line of each point and the medial margin of the brachial or ulnar artery; A_MN, the angle between the vertical line of the each point and the medial border of the median nerve; $A \_A$, the angle between the vertical line of each point and the medial border of ulnar or brachial artery. If the medial end of the PT was located lateral to the vertical line of each point, the P_PT1 was recorded as a negative value (-).

${ }^{a)} \mathrm{p}<0.05$, between level 0 and level 3 ; ${ }^{\text {b }} \mathrm{p}<0.05$, between level 1 and level 2,$3 ;{ }^{\text {c) }} \mathrm{p}<0.05$, between level 2 and level 1,3 ; ${ }^{d)} \mathrm{p}<0.05$, among four levels; ${ }^{\text {e) }} \mathrm{p}<0.05$, between level 1 and level 2 ; ${ }^{\mathrm{f}} \mathrm{p}<0.05$, between level 2 and level 0,$3 ;{ }^{\text {g) }} \mathrm{p}<0.05$, between level 0 and level 2,$3 ;{ }^{\text {h) }} \mathrm{p}<0.05$, between level 2 and level 0,$1 ;{ }^{\mathrm{i}} \mathrm{p}<0.05$, between level 3 and level 0,$1 ;{ }^{\mathrm{j}} \mathrm{p}<0.05$, between level 1 and level 0,$3 ;{ }^{k} \mathrm{p}<0.05$, between level 2 and level $0 ;{ }^{1)} \mathrm{p}<0.05$, between level 0 and level 1,3 .

the PT has become identifiable.

There have been several articles regarding the evaluation of needle electrode insertion sites using ultrasonography [9-11]. However, there have been no studies regarding an insertion site for the PT. To our knowledge, this is the first study to establish an accurate and safe approach to needle electromyography of the PT muscle using ultrasonographic study.

In order to avoid the median nerve and brachial or ulnar artery, it is safest to insert the needle medial to the vertical line and where the muscle is thick enough. Thus, the level with the longest distance between a vertical line and medial margin of PT and the thickness of the muscle were considered to be the optimal level.

In the case of men, there was no significant difference between muscle thickness at points 1 and 2. The muscle was thickest at point 2 and the distance from the muscle to the median nerve was $1 \mathrm{~cm}$ at its shortest, which could lead to possible nerve injury when the needle is inserted laterally. The distance between the expected needle insertion line and the medial margin of the muscle was lon- gest at point 1 , and this was significantly different from point 2. In women, on the other hand, the muscle was thickest at point 1 but the difference between it and point 2 was only $0.01 \mathrm{~cm}$ on average, which was not significant. The distance between the needle insertion line and the medial margin of the muscle was the longest at point 1 , which was same as in men, and this was significantly different from point 2 . At point 3 , the needle did not meet the muscle in women. The difference between men and women seems to be due to difference in the length of their respective forearms.

According to this study's results, both men and women had neurovascular bundles located lateral to the needle insertion line. Among the bundle, the medial placement of median nerve compared to the artery was prominent, which indicates higher risk of injury to the nerve than the vessels when the needle in inserted laterally.

Therefore, in order to prevent nerve injury, it is recommended that the needle be inserted $2-3.5 \mathrm{~cm}$ distal to the mid-point between the biceps tendon and medial epicondyle in the elbow crease, and the needle should 
Level 0

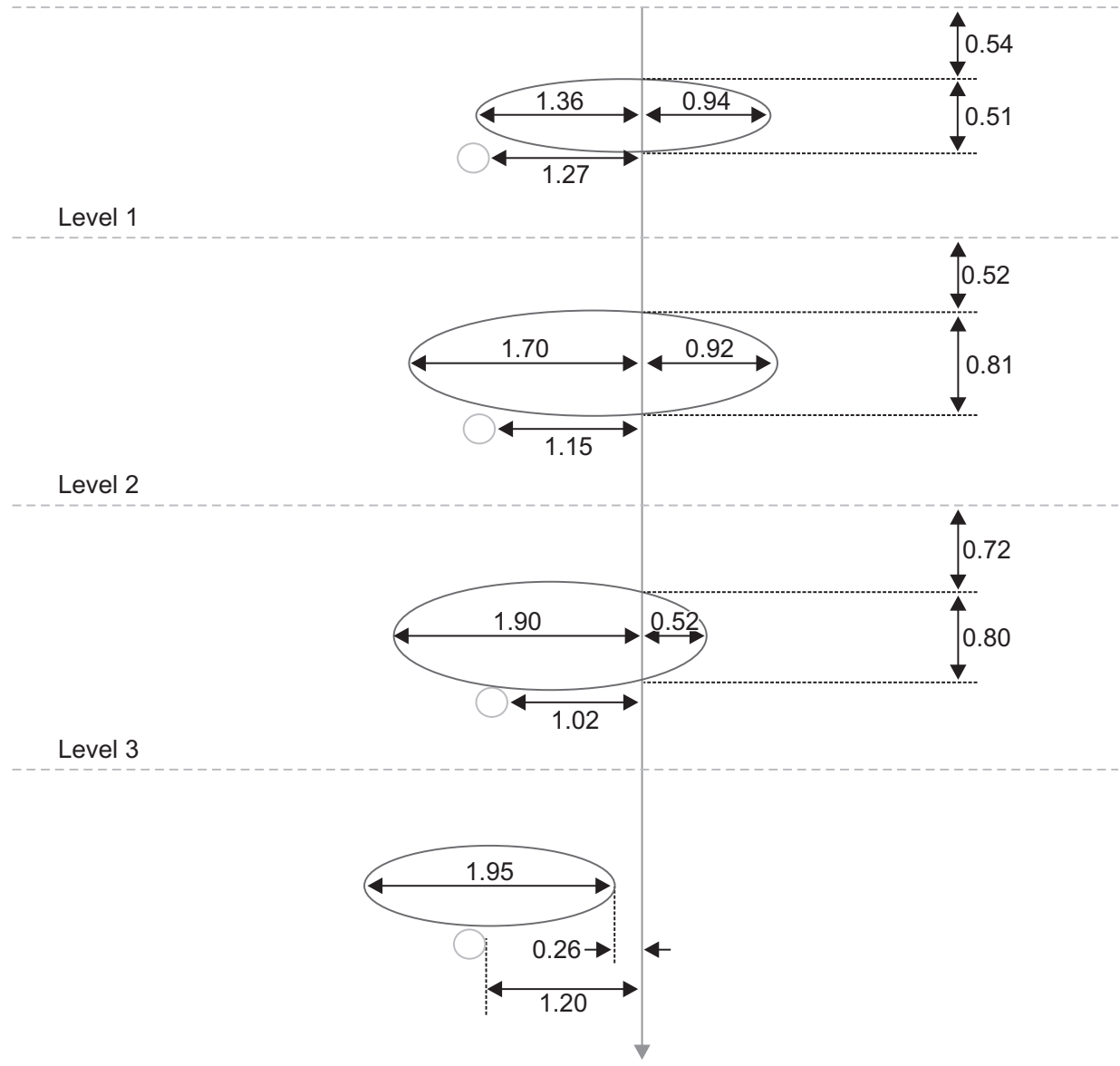

Fig. 4. In women, schematic drawing of relationship the distance between the vertical needle insertion line (red arrow) and the medial or lateral margin of the pronator teres (orange oval), the distance between the vertical needle insertion line and the medial margin of the median nerve (yellow circle), and the distance between skin (yellow dot line) and upper or lower margin of pronator teres. be advanced in the direction distal $2 \mathrm{~cm}$ toward the elbow crease and medially, within $1 \mathrm{~cm}$ in men and $0.5 \mathrm{~cm}$ in women, to prevent from inserting into inappropriate muscle. The direction for needle exploration is a concordant result to a previous cadaver study [12]. Widely used methods for the electromyography of PT muscle were insertion of a needle electrode two fingerbreadths distal to the midpoint of the medial epicondyle and the tendon of biceps brachii muscle $[1,2]$ or $2.5 \mathrm{~cm}$ distal to the elbow crease in the same direction as the PT muscle [13], or 5 $\mathrm{cm}$ distal to the midpoint of the elbow crease [14], irrespective of the gender. This study provides not only the safe needle insertion point for the PT muscle, but also different range for needle exploration in each gender.

This study has several potential limitations. The first limitation is the quantity of subjects. Second, in the ultrasound image, we assumed the posterior acoustic shadowing of a broken needle on the skin as a needle insertion line instead of inserting a real needle. Third, because the linear probe has difficulty conforming to the curva- ture of the forearm without compression, such irregular compression of a probe can induce measurement errors. In order to reduce such errors, many trials such as using a water tank to use water as a transmission medium to free the probe from compression have been done [9]. In this study, the use of a water tank was limited due to the position of the arm, which was in full extension. Instead, we used abundant amount of gel in order to minimize probe compression and thus minimize the migration or change to the inner structures. Lastly, only healthy people were included in this study. Patients with C7 radiculopathy or other diseases, such as median neuropathy, will have different results due to muscle atrophy. Thus, further study needs to be done including such patients.

In conclusion, for needle electrode insertion into the PT, ultrasound imaging allows a more accurate and safe approach. The results of this study prove that the most appropriate and safe needle insertion site to the PT is distal 2-3.5 cm to the mid-point between the biceps tendon and medial epicondyle in the elbow crease. Once the 
needle is inserted perpendicular to the skin's surface at the above site until the needle reaches the PT, the needle must be advanced to the proximal and medial side within $1 \mathrm{~cm}$ in men and $0.5 \mathrm{~cm}$ in women, to avoid median nerve or ulnar artery injury.

\section{CONFLICT OF INTEREST}

No potential conflict of interest relevant to this article was reported.

\section{REFERENCES}

1. Perotto AO. Anatomical guide for the electromyographer: the limb and trunk. 3rd ed. Springfield: Charles C Thomas Publisher; 1994.

2. Preston DC, Shapiro BE. Electromyography and neuromuscular disorders: clinical-electrophysiologic correlations. 3rd ed. New York: Elsevier Saunders; 2013.

3. Al-Shekhlee A, Shapiro BE, Preston DC. Iatrogenic complications and risks of nerve conduction studies and needle electromyography. Muscle Nerve 2003; 27:517-26.

4. Lee HJ, DeLisa JA. Manual of nerve conduction study and surface anatomy for needle electromyography. 4th ed. Philadelphia: Lippincott Wilkins and Williams; 2005.

5. Zupko RE. A dictionary of weights and measures for the British Isles: the Middle Ages to the twentieth century. Philadelphia: American Philosophical Society; 1985.
6. Canovas F, Mouilleron P, Bonnel F. Biometry of the muscular branches of the median nerve to the forearm. Clin Anat 1998;11:239-45.

7. Rodriguez-Niedenfuhr M, Vazquez T, Nearn L, Ferreira B, Parkin I, Sanudo JR. Variations of the arterial pattern in the upper limb revisited: a morphological and statistical study, with a review of the literature. J Anat 2001;199(Pt 5):547-66.

8. Jenkins DB. Hollinshead's functional anatomy of the limbs and back. 9th ed. St. Louis: Saunders; 2009.

9. Lee SM, Kim K, Lee SM, Lee HS. Ultrasonographic evaluation of needle insertion site for the flexor pollicis longus. Ann Rehabil Med 2013;37:215-20.

10. Won SJ, Kim JY, Yoon JS, Kim SJ. Ultrasonographic evaluation of needle electromyography insertion into the tibialis posterior using a posterior approach. Arch Phys Med Rehabil 2011;92:1921-3.

11. Rha DW, Im SH, Lee SC, Kim SK. Needle insertion into the tibialis posterior: ultrasonographic evaluation of an anterior approach. Arch Phys Med Rehabil 2010;91:283-7.

12. Kim IJ, Kang HS, Kim BJ, Kim LN, Hwang MR, Kim $\mathrm{DH}$. Comparison of the electromyography needle insertion sites for the pronator teres muscle. J Korean EMG Electrodiagn Med 2010;12:83-6.

13. Chu-Andrews J, Johnson RJ. Electrodiagnosis: an anatomical and clinical approach. Philadelphia: Lippincott Williams \& Wilkins; 1986.

14. Lee HJ, DeLisa JA. Surface anatomy for clinical needle electromyography. New York: Demos Medical Publishing; 2000. 